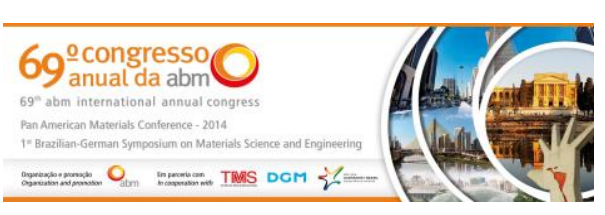

Tema: Iniciação Científico-Tecnológica

\title{
SIMULAÇÃO MATEMÁTICA DO ESCOAMENTO BIFÁSICO NO INTERIOR DO MODELO FÍSICO DO DISTRIBUIDOR DE LINGOTAMENTO CONTÍNUO*
}

\author{
Larissa de Barros Machado Vilela ${ }^{1}$ \\ Ricardo Luiz Perez Terixeira² \\ Leonardo Neves ${ }^{3}$
}

\section{Resumo}

O lingotamento contínuo é um processo de solidificação de aço líquido onde o conhecimento de suas variáveis é de extrema importância para a produção de aços de qualidade. Este processo contém um reator denominado distribuidor que se localiza entre a panela e o molde e tem como função tradicional, distribuir o aço que sai da panela para o molde, mas também realiza outras importantes funções. Devido a essa importância no processo, este trabalho objetivou realizar o estudo do escoamento do aço no distribuidor com duas configurações diferentes, sendo uma sem injeção de gás inerte e a outra com injeção de gás inerte. Neste estudo foram utilizados softwares para a realização das simulações matemáticas onde se podem notar as diferenças das curvas DTR, grandezas de turbulência e perfil de velocidade quando se tem ou não a injeção de gás inerte.

Palavras-chave: Simulação matemática; Escoamento bifásico; Distribuidor; Lingotamento contínuo.

\section{MATHEMATICAL SIMULATION OF TWO-PHASE FLOW INSIDE THE PHYSICAL MODEL OF CONTINUOUS CASTING TUNDISH}

\begin{abstract}
The continuous casting is a steel solidification process which is very important to have good knowledge about its variables in order to produce steel with good quality. The process works with a reactor called tundish in between the ladle and molde (die) distributing the steel that comes from the ladle to the molde as the traditional function, besides, it also have some others important functions. Because of its importance in the process, this work aim to realize studies on the steel flow in the tundish with two different setups, one with inert gas injection and another one without it. Computer's simulation software were used to make the mathematical simulations making possible to note the curves' difference DTR, largeness turbulence and speed profile with or without inert gas' injection.
\end{abstract}

Keywords: Mathematical simulation; Two-phase flow; Tundish; Continuous casting.

1 Graduanda em Engenharia Metalúrgica, Universidade do Estado de Minas Gerais (UEMG), João Monlevade, MG, Brasil.

2 Eng. Químico, Professor, Pesquisador, Dr. em Engenharia Metalúrgica e de Materiais, Universidade Federal de Itajubá (UNIFEI), Itabira, MG, Brasil.

3 Eng. Metalurgista, Professor, Pesquisador, Dr. em Engenharia Metalúrgica e de Materiais, Universidade do Estado de Minas Gerais (UEMG), Departamento de Engenharia Metalúrgica, João Monlevade, MG, Brasil.

* Contribuição técnica ao $69^{\circ}$ Congresso Anual da ABM - Internacional e ao 14ํㅡㄹ ENEMET - Encontro Nacional de Estudantes de Engenharia Metalúrgica, de Materiais e de Minas, 21 a 25 de julho de 2014, São Paulo, SP, Brasil. 


\section{INTRODUÇÃO}

O lingotamento contínuo é um processo de solidificação de aço líquido muito importante se comparado ao lingotamento convencional devido à alta produtividade e rendimento, excelente qualidade superficial e interna do aço. O conhecimento de suas variáveis é de extrema importância para a produção de aços de qualidade.

No lingotamento contínuo são basicamente utilizados três reatores metalúrgicos: a panela de aço, o distribuidor e o molde do lingotamento. O distribuidor se localiza entre a panela e o molde, tem como função tradicional, distribuir o aço que sai da panela para o molde. Este reator pode apresentar formas variadas e modificadores de fluxo que auxiliam no controle do processo de lingotamento com a finalidade de produzir um aço de alta qualidade e/ou aumento da produção. Exemplos desses modificadores são: diques, barragens, injeção de gases, inibidores de turbulência dentre outros.

Devido à busca por melhorias na produção de aço, o distribuidor atualmente realiza várias funções metalúrgicas além da distribuição do mesmo. Assim surgiu uma nova área de estudo denominada metalurgia do distribuidor e viu-se a importância de um estudo mais detalhado sobre este reator.

O objetivo deste trabalho foi realizar o estudo do escoamento do aço em um distribuidor de lingotamento contínuo com duas configurações diferentes, sendo uma sem injeção de gás e a outra com injeção de gás inerte.

\subsection{Revisão da Literatura}

\subsubsection{Distribuidor do lingotamento contínuo}

O distribuidor tem como principais funções servir de reservatório de aço e de manter a continuidade do processo de lingotamento contínuo. É também projetado com a finalidade de realizar várias operações metalúrgicas como: separação e flotação de inclusões, modificação da morfologia das inclusões formadas, ajuste fino da composição química, controle do superaquecimento e homogeneização térmica e química do aço.

Devido à busca constante pela qualidade, o escoamento do aço líquido no distribuidor passou a receber maior atenção. Modelagens matemáticas e físicas do fluxo do aço entre a panela e molde têm sido feitas a fim de estudar o comportamento do fluxo de aço dentro do distribuidor. De acordo com Szekely e llegbusi [1] e Shade et al. citado por Neves [2], o distribuidor contem três zonas distintas de fluxo, definidas como:

- zona de fluxo pistonado: é a fração do volume total do distribuidor em que a velocidade pontual é máxima, na qual dita o tempo mínimo de residência do aço no distribuidor. Quanto maior for seu valor, melhor será para a flotação das inclusões não-metálicas;

- zona de mistura perfeita: é a fração que contribui para a eliminação de gradientes de temperatura e de composição química do metal líquido. Esta região caracteriza-se por um gradiente de velocidade que causa turbulência e assim pode promover o arraste de inclusões não-metálicas para dentro do aço líquido, distúrbios na flotação das inclusões não metálicas e aumento da taxa de reoxidação do metal líquido;

- zona de volume morto: é a fração do volume total do distribuidor que possui velocidade tão baixa que pode ser considerada estagnada. É uma zona indesejável, pois reduz efetivamente o volume útil do distribuidor, além de

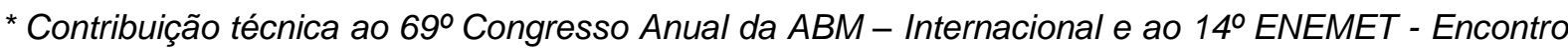
Nacional de Estudantes de Engenharia Metalúrgica, de Materiais e de Minas, 21 a 25 de julho de 2014, São Paulo, SP, Brasil.
} 


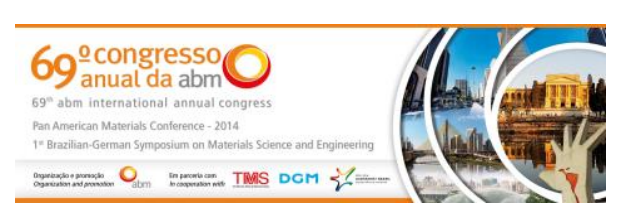

provocar perda de temperatura do banho e a segregação de elementos químicos. A presença dessa zona indica ineficiência no uso do volume do distribuidor.

Segundo Singh e Koria [3], há outra zona de fluxo no distribuidor denominada "curtocircuito". Esta zona é representada pela porção do fluido que entra no distribuidor, movimenta-se pelo fundo do mesmo e escapa, em um curto intervalo de tempo, sem permitir que as inclusões existentes nesta porção do aço líquido tenham chances de escapar até a superfície. Esta zona é indesejável e deve ser eliminada, uma vez que reduz o tempo mínimo de residência do metal líquido no distribuidor. De acordo com os autores as condições hidrodinâmicas que o distribuidor deve satisfazer são:

- mínimo volume morto, com o propósito de minimizar a segregação e a perda de temperatura do aço líquido no distribuidor;

- máxima fração de volume pistonado para favorecer a remoção de inclusões nãometálicas;

- máxima região de mistura perfeita para favorecer a coalescência das inclusões não-metálicas de pequenas dimensões;

- mínimo volume de "curto-circuito" para inibir o arraste das inclusões nãometálicas do aço líquido;

- faixa mínima de variação dos tempos de residências do metal líquido no distribuidor.

\subsubsection{Dispositivos modificadores de fluxo}

A utilização dos dispositivos modificadores de fluxo, tais como diques, barragens e inibidores de turbulência são colocados no distribuidor com o objetivo de modificar o fluxo do aço líquido. É uma alternativa utilizada para a otimização do projeto de distribuidor do lingotamento contínuo e, consequentemente, do escoamento do metal líquido.

Os diques e barragens são anteparos colocados transversalmente ao comprimento do distribuidor, sendo o dique na parte superior e a barragem na parte inferior. Os diques podem ser utilizados para garantir a retenção de escória proveniente da panela e ajudar na contenção da turbulência próxima à região de entrada e as barragens para eliminar o "curto-circuito", criar um fluxo de aço na direção da superfície livre, o que contribui para que as inclusões sejam capturadas e restringir a turbulência do jato de aço na região de entrada. O inibidor de turbulência é uma caixa aberta que é colocada no fundo do distribuidor sob a válvula longa (válvula de alimentação) com o objetivo de reduzir a turbulência gerada pelo jato de entrada.

Outro artifício utilizado é a injeção de gás inerte que pode trazer muitos benefícios ao distribuidor. O gás, injetado no fundo do distribuidor, tem como principal objetivo a flotação de inclusões não-metálicas do aço líquido. Ele pode ser também injetado em regiões pontuais visando à redução de zonas de volume morto e assim contribuindo para homogeneização térmica e química do aço. A cortina de gás inerte pode servir para diminuir a zona de "curto-circuito", aumentando teoricamente o tempo mínimo de residência do aço no distribuidor. É preciso atenção na vazão de gás, pois altas vazões podem agitar a superfície do banho metálico e arrastar escória para o aço líquido segundo Neves [2].

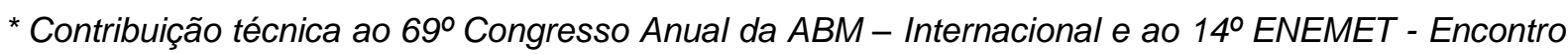
Nacional de Estudantes de Engenharia Metalúrgica, de Materiais e de Minas, 21 a 25 de julho de 2014, São Paulo, SP, Brasil.
} 


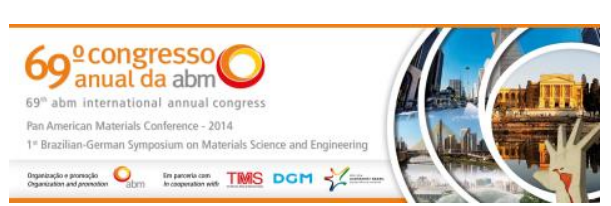

\subsubsection{Curvas de distribuição de tempos de residência}

O estudo da curva de distribuição de tempo de residência busca avaliar e otimizar o fluxo de aço no distribuidor de lingotamento contínuo. O tempo médio, ou nominal, de residência de um elemento fluido no sistema pode ser calculado pela fórmula:

$$
t_{\text {teórico }}=\frac{\text { volume do reator }}{\text { vazão volumétrica através do reator }}
$$

O tempo de residência do fluido no interior do reator também pode ser determinado por meio da adição de traçadores. Esta técnica consiste na adição de um material no fluxo de entrada do reator e medir sua concentração na saída. O material pode ser um corante, substância química ou material radioativo.

São diversas técnicas utilizadas para adição de traçador no reator, mas as duas que se destacam são:

- adição contínua do traçador na entrada, iniciada em um instante definido ("step input");

- adição de uma quantidade de traçador por um curto intervalo de tempo desprezível em relação ao tempo médio de residência do fluido no reator (injeção de um pulso - "pulse input").

A técnica de adição de traçador mais adotada mais adotada é a de injeção de pulso e os resultados obtidos podem ser representados graficamente utilizando concentração e tempo adimensionais como as equações abaixo mostram.

$$
\begin{aligned}
& C=\frac{c}{q / V_{\text {dist }}} \\
& \theta=\frac{t}{t_{\text {teórico }}}
\end{aligned}
$$

em que:

$C=$ concentração adimensional;

$c=$ concentração de traçador na saída a cada instante $t\left(\mathrm{~kg} / \mathrm{m}^{3}\right)$;

$q=$ quantodade de traçador injetado $(\mathrm{kg})$;

$V_{\text {dist }}=$ volume do distribuidor $\left(\mathrm{m}^{3}\right)$;

$\theta=$ tempo adimensional;

$t=$ tempo $(\mathrm{s})$;

tteórico $=$ tempo de residência nominal do reator $(s)$.

Com a injeção em pulso é possível obter a curva de distribuição de tempos de residência (DTR). A resposta normalizada é denominada curva $\mathrm{C}$ e é obtida pela divisão da concentração medida pela área sob a curva da concentração versus o tempo. Esta curva permite avaliar os aspectos do escoamento do aço no interior do reator e determinar os volumes das zonas de escoamento pistonado, mistura perfeita e volume morto.

\subsubsection{Abordagem Euleriana-Euleriana}

Segundo Paladino [4] há várias classificações para modelos multifásicos. Uma das mais utilizadas na literatura classifica o modelo em abordagem Euleriana-Euleriana. Nesta abordagem, cada fase tem seu próprio campo de variáveis (pressão, temperatura, etc.), cada uma acoplada pelos modelos de transferência de quantidade de movimento, energia e massa. Os modelos de transferência mais simples assumem uma divisão no campo de pressão.

O princípio de conservação leva em consideração um volume de controle genérico com uma interface, como pode ser visto na Figura 1 a seguir.

\footnotetext{
* Contribuição técnica ao $69^{\circ}$ Congresso Anual da ABM - Internacional e ao 14ํㅡㄹ ENEMET - Encontro Nacional de Estudantes de Engenharia Metalúrgica, de Materiais e de Minas, 21 a 25 de julho de 2014, São Paulo, SP, Brasil.
} 

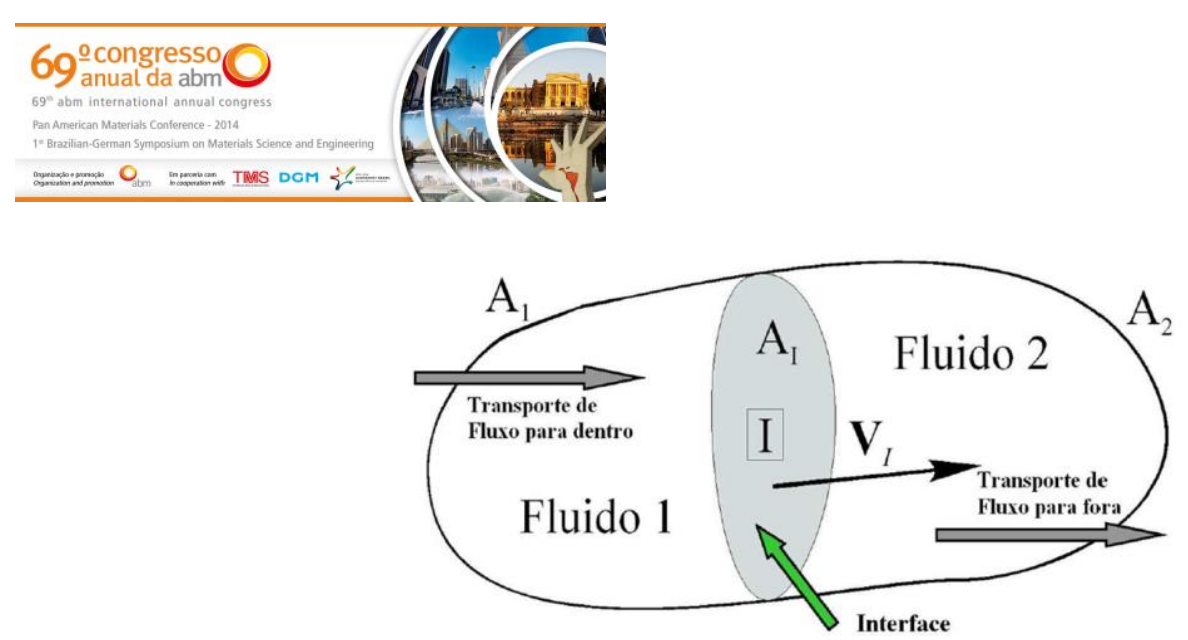

Figura 1. Volume de controle genérico com uma interface [5].

A equação de continuidade para a fase $\alpha$ é expressa por Neves [2]:

$$
\frac{\partial}{\partial t}\left(r_{\alpha} \rho_{\alpha}\right)+\nabla\left(r_{\alpha} \rho_{\alpha} u_{\alpha}\right)=\sum_{\beta=1}^{N}\left(M_{\alpha \beta}-M_{\beta \alpha}\right)
$$

em que:

$r_{\alpha}=$ fração de volume da fase $\alpha$;

$\rho_{\alpha}=$ densidade da fase $\alpha$;

$u_{\alpha}=$ velocidade da fase $\alpha$;

$N=$ número total de fases ;

$M_{\alpha \beta}=$ taxa de transferência de massa da fase $\alpha$ para a fase $\beta$;

$M_{\beta \alpha}=$ taxa de transferência de massa da fase $\beta$ para a fase $\alpha$.

A soma das frações de volumes das fases é unitária:

$$
\sum_{\propto} r_{\propto}=1
$$

A equação de conservação de quantidade de movimento na direção $x$ pode ser expressa por:

$$
\frac{\partial\left(\rho_{\alpha} r_{\alpha} u_{\alpha}\right)}{\partial t}+\frac{\partial\left(\rho_{\alpha} r_{\alpha} u_{\alpha} u_{\alpha}\right)}{\partial x}=-r_{\alpha} \cdot \frac{\partial P}{\partial x}+\frac{\partial\left(r_{\alpha} \tau_{\alpha}\right)}{\partial x}+r_{\alpha} \rho_{\alpha} g+S_{M \alpha}+M_{I \alpha}
$$

sendo:

em que:

$$
\begin{aligned}
& S_{M \alpha}=F_{D}+F_{L}+F_{M}+F_{T}+F_{W} \\
& M_{I \alpha}=\sum_{\beta=1}^{N}\left(M_{\alpha \beta} \cdot u_{\beta}-M_{\beta \alpha} \cdot u_{\alpha}\right)
\end{aligned}
$$

$r_{\alpha}=$ fração da fase $\alpha$;

$\rho_{\alpha}=$ densidade da fase $\alpha\left(\mathrm{kg} / \mathrm{m}^{3}\right)$;

$u_{\alpha}=$ velocidade da fase $\alpha(\mathrm{m} / \mathrm{s})$;

$u_{\beta}=$ velocidade da fase $\beta(\mathrm{m} / \mathrm{s})$;

$P=$ pressão $(\mathrm{Pa})$;

$\tau_{\alpha}=$ tensão cisalhamento que atua na fase $\alpha\left(\mathrm{kg} / \mathrm{m} . \mathrm{s}^{2}\right)$;

$G=$ aceleração da gravidade $\left(\mathrm{m} / \mathrm{s}^{2}\right)$.

O termo S é a soma das forças interfaciais (arraste FD ("drag"), sustentação FL ("lift"), massa virtual FM ("virtual mass") dispersão turbulenta FT ("turbulent dispersion"), lubrificação da parede FW ("wall lubrication") e a transferência de quantidade de movimento associada com a transferência de massa. MI descreve as forças que atuam na fase devido à presença da fase.

As forças que atuam em uma fase são de mesma magnitude e em sentido oposto às que atuam na fase, logo o somatório das forças entre as fases se anula.

$$
M_{\alpha \beta} u_{\beta}=-M_{\beta \alpha} u_{\alpha}=\sum_{\alpha} M_{\alpha} U=0
$$

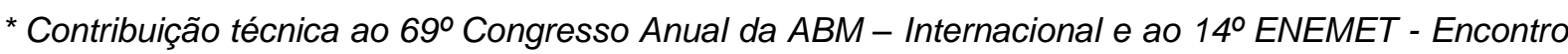
Nacional de Estudantes de Engenharia Metalúrgica, de Materiais e de Minas, 21 a 25 de julho de 2014, São Paulo, SP, Brasil.
} 


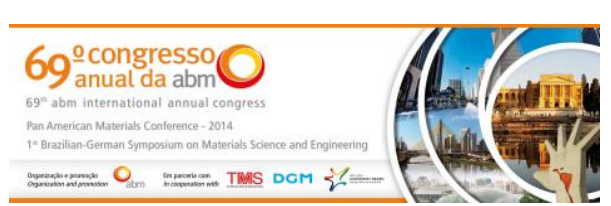

A quantidade de movimento transportada entre as fases é devido às forças de arraste e à transferência de massa.

\section{MATERIAIS E MÉTODOS}

A modelagem matemática do escoamento do aço foi feita para o estudo das condições fluidodinâmicas no distribuidor de lingotamento contínuo. Foram realizadas simulações com diferentes configurações do reator considerando 0 escoamento tridimensional bifásico ar/água. O estudo foi realizado por meio de softwares.

Utilizando de técnicas computacionais, este trabalho analisou principalmente os seguintes aspectos:

- Efeito do escoamento ar/água no modelo físico no distribuidor com os modificadores de fluxo dique e barragem sem injeção de gás;

- Efeito do escoamento ar/água no modelo físico do distribuidor com dique e injeção de gás no lugar da barragem;

- Curvas DTR, grandezas de turbulência e perfil de velocidade.

A seguir serão abordadas as condições de contorno, as características do distribuidor com as respectivas relações matemáticas entre o modelo físico e equipamento industrial e os métodos matemáticos que foram utilizados para os estudos propostos. As condições de contorno do modelo matemático foram estabelecidas de acordo com as condições físicas nos contornos do domínio do distribuidor.

A Figura 2 mostra uma vista do domínio de simulação e as condições propostas para as configurações de distribuidor proposta.

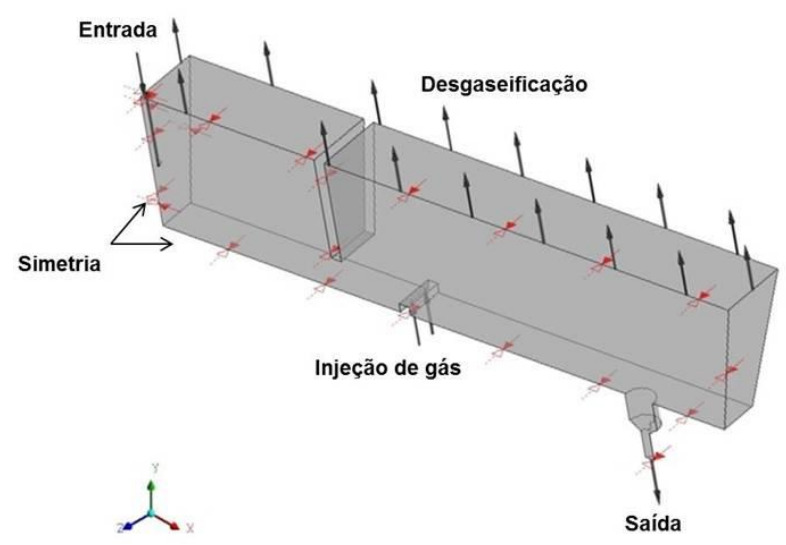

Figura 2. Domínio do distribuidor utilizado nas simulações.

As condições de contorno no distribuidor foram;

- Paredes:

Foi considerada a condição de não escorregamento. Para os gases, foi assumida a condição de escorregamento livre ("free slip").

- Bicos de injeção;

Foi considerada a entrada de gases. A vazão mássica de entrada de ar no modelo computacional foi de $3,95 \times 10^{-5} \mathrm{~kg} / \mathrm{s}$ (2 NI/min).

- Superfície livre do distribuidor:

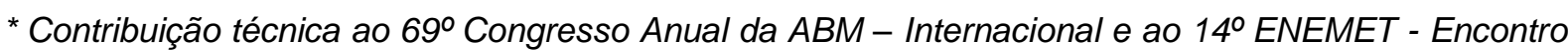
Nacional de Estudantes de Engenharia Metalúrgica, de Materiais e de Minas, 21 a 25 de julho de 2014, São Paulo, SP, Brasil.
} 


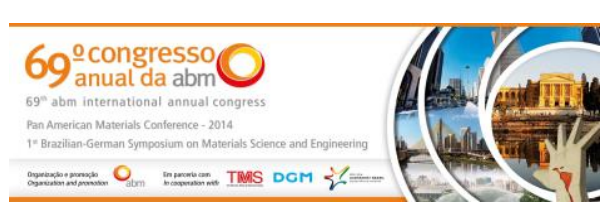

Tabela 2. Característica do sistema de injeção de gases utilizados no distribuidor

\begin{tabular}{|l|c|}
\hline \multicolumn{1}{|c|}{ Parâmetros } & Injeção de gás \\
\hline Injeção de gás no fundo: & 2 \\
vazão de gás (I/min) & 4 \\
número de bicos & 1 \\
diâmetro dos bicos $(\mathrm{mm})$ & \\
\hline
\end{tabular}

No modelo computacional do distribuidor, na fase líquida, é utilizado água em vez do aço líquido, pois segundo Barbosa [6] a viscosidade cinemática $(\mu / \rho)$ da água na temperatura ambiente $\left(25^{\circ} \mathrm{C}\right)$ é aproximadamente igual a do aço a $1600^{\circ} \mathrm{C}$ como pode ser visto pela Tabela 3.

Tabela 3. Viscosidade cinemática da água e do aço

\begin{tabular}{|c|c|c|}
\hline & Temperatura $\left({ }^{\circ} \mathrm{C}\right)$ & $\mu / \rho\left(\mathrm{m}_{2} / \mathrm{s}\right)$ \\
\hline Água & 25 & $1,00 \times 10-6$ \\
\hline Aço & 1600 & $9,13 \times 10-7$ \\
\hline
\end{tabular}

\subsection{Métodos Matemáticos}

No escoamento turbulento será utilizado o modelo do tipo $k-\varepsilon$. Para o modelo multifásico será utilizado o modelo de Grace para simular a força de arraste. $O$ critério de convergência, RMS, a ser utilizado para as equações em geral para resolução dos equacionamentos será de $10^{-6}$.

Este estudo foi desenvolvido na Faculdade de Engenharia (FaEnge) da Universidade do Estado de Minas Gerais (UEMG), campus João Monlevade com apoio da Universidade Federal de Minas Gerais (UFMG). Foi utilizado para a realização das simulações os softwares SolidWorks e Ansys Academic.

\section{RESULTADOS E DISCUSSÃO}

À análise de independência de malha para o modelo matemático sem injeção de gás foi feita utilizando as malhas de 168.467, 249.784, 290.752 e 458.679 elementos de volume. E para o modelo matemático com injeção de gás foi utilizada as malhas de $304.074,453.492$ e 556.563 elementos de volume. Para a escolha da melhor malha foi utilizado a curva DTR das simulações e encontrou-se para o modelo sem injeção e com injeção de gás as malhas de 290.752 e 304.074 respectivamente.

\footnotetext{
* Contribuição técnica ao $69^{\circ}$ Congresso Anual da ABM - Internacional e ao 14ํㅡㄹ ENEMET - Encontro Nacional de Estudantes de Engenharia Metalúrgica, de Materiais e de Minas, 21 a 25 de julho de 2014, São Paulo, SP, Brasil.
} 

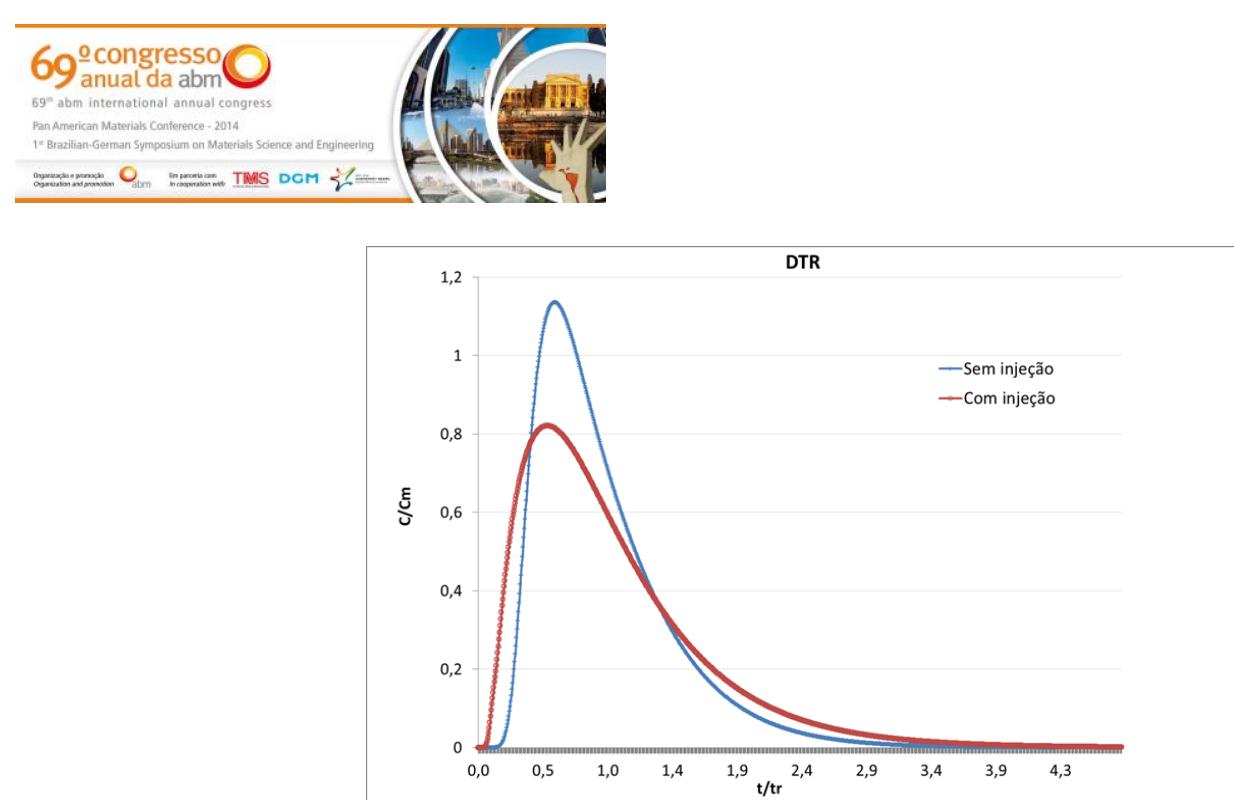

Figura 3. Comparação das curvas DTR obtidas nas simulações matemáticas do distribuidor sem injeção de gás e com injeção de gás.

As análises visual e numérica são importantes métodos para observação e quantificação, respectivamente, dos efeitos gerados ao se adotar diferentes configurações. As análises numéricas foram feitas pela utilização das frações de volume pistonado, mistura e morto. Foram utilizados também o tempo mínimo de residência, $t_{\min }$, que representa o tempo de início de saída do distribuidor, o tempo máximo, tmáx, representando o tempo de ocorrência da concentração máxima na saída do distribuidor e o tempo de residência médio, tmédio, que foi calculado pela expressão 10.

em que:

$$
t_{\text {médio }}=\frac{\sum_{t=0}^{t=2 . t_{\text {teórico }} C_{i} t_{i} \Delta t_{i}}}{\sum_{t=0}^{t=2 . t} \text { teórico } C_{i} \Delta_{i}}
$$

$t_{\text {médio }}=$ tempo de residência médio real (s);

$t_{\text {teórico }}=$ tempo teórico de residência $(\mathrm{s})$;

$t_{i}=$ tempo de residência i $(\mathrm{s})$;

$t_{i}=$ variação de tempo do instante inicial até o instante i (s);

$C_{i}=$ concentração do traçador em um tempo t.

A Tabela 3 apresenta os resultados da configuração com e sem injeção de gás. Os valores estimados são informações obtidas na curva DTR pela dispersão da concentração do traçador. Os valores calculados são obtidos de acordo com a técnica desenvolvida por Sahai e Emi [7] de utilizar equações para obter parâmetros para caracterizar o fluxo do distribuidor.

Nota-se que todos os valores, exceto volume de mistura, foram maiores para o sistema sem injeção do que com a injeção.

Tabela 3. Valores estimados e calculados para as configurações com e sem injeção de gás

\begin{tabular}{|c|c|c|c|c|c|c|c|}
\cline { 2 - 8 } \multicolumn{1}{c|}{} & \multicolumn{3}{c|}{ Valores Estimados } & \multicolumn{4}{c|}{ Valores Calculados } \\
\cline { 2 - 8 } \multicolumn{1}{c|}{} & $\mathrm{t}_{\min }(\mathrm{s})$ & $\mathrm{t}_{\text {máx }}(\mathrm{s})$ & $\mathrm{C}_{\mathrm{n} \text {, máx }}$ & $\mathrm{t}_{\text {médio }}(\mathrm{s})$ & $\mathrm{V}_{\text {morto }} / \mathrm{V}$ & $\mathrm{V}_{\text {pistonado }} / \mathrm{V}$ & $\mathrm{V}_{\text {mistura }} / \mathrm{V}$ \\
\hline Sem injeção & 38,34 & 127,8 & 1,14 & 172,15 & 0,20 & 0,13 & 0,70 \\
\hline Com injeção & 10,65 & 115,0 & 0,82 & 161,68 & 0,17 & 0,07 & 0,74 \\
\hline
\end{tabular}

A Figura 4 mostra o campo de vetores de velocidade a partir de um corte longitudinal para as configurações sem e com injeção de ar. A distribuição de velocidade é praticamente a mesma até o dique para as duas configurações utilizadas, sendo que

* Contribuição técnica ao $69^{\circ}$ Congresso Anual da ABM - Internacional e ao 14ํㅡㄹ ENEMET - Encontro Nacional de Estudantes de Engenharia Metalúrgica, de Materiais e de Minas, 21 a 25 de julho de 2014, São Paulo, SP, Brasil. 
a configuração sem injeção de ar tem um ponto de recirculação de água nesta região. A partir deste ponto, o fluxo de água sofre alteração devido as diferentes configurações.

Após o dique nota-se na configuração sem injeção de ar outro ponto de recirculação após a barragem e a velocidade se mantém praticamente a mesma até chegar à saída. Com a injeção de ar ocorrem duas regiões de recirculação, uma antes e uma após a injeção de ar. Há também nessa condição uma variação maior de velocidade principalmente próximo à injeção.

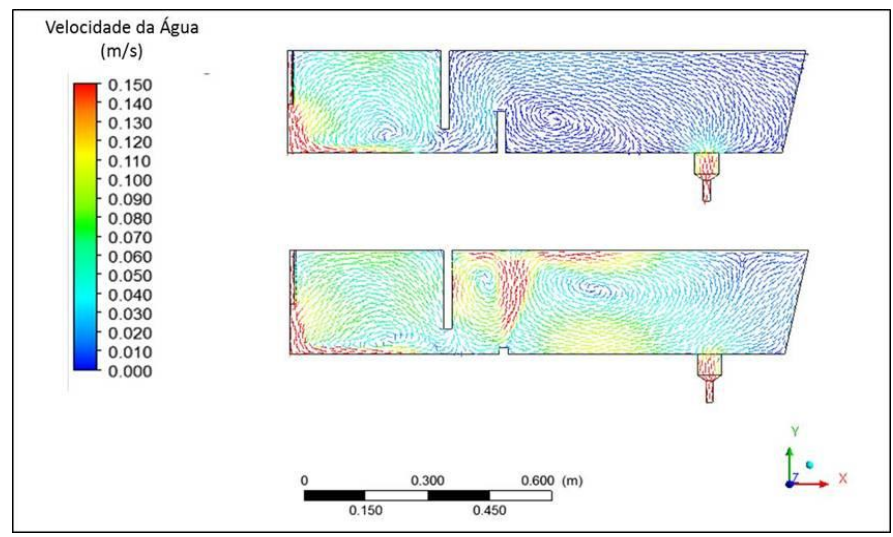

Figura 4. Comparação dos vetores de velocidade a partir de um corte longitudinal no modelo físico do distribuidor sem injeção de gás e com injeção de gás.

A Figura 5 mostra a fração de volume de gás no plano de um corte transversal na seção de injeção de ar.

Com a injeção de ar uma fina camada adjacente à parede tem uma passagem de água livre da interferência de ar.

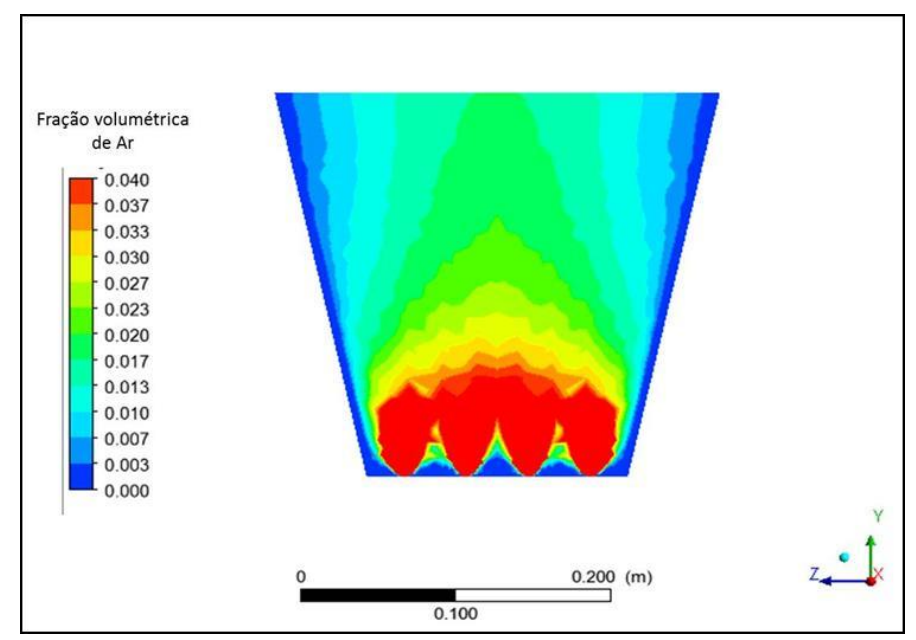

Figura 5. Fração de gás obtida na simulação matemática do modelo físico do distribuidor para a configuração com injeção de gás.

\section{CONCLUSÃO}

A simulação matemática do modelo físico do distribuidor foi feita com duas configurações de distribuidor diferentes, uma sem injeção de ar e outra com injeção de ar no lugar da barragem.

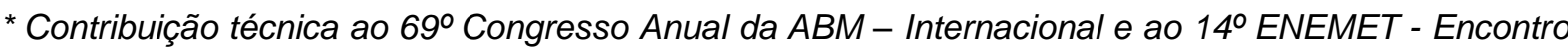
Nacional de Estudantes de Engenharia Metalúrgica, de Materiais e de Minas, 21 a 25 de julho de 2014, São Paulo, SP, Brasil.
} 


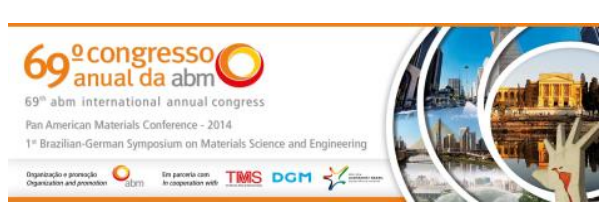

Considerando as condições ideais de mínimo volume morto e tempo médio de residência e máximo volume pistonado e de mistura que o distribuidor deve ter segundo Singh e Koria [4], a configuração que melhor satisfaz essas condições é a que possui a injeção de ar.

\section{Agradecimentos}

Aos professores e orientadores Leonardo Neves e Ricardo Luiz Perez Teixeira, pela disponibilidade e orientação durante o desenvolvimento deste projeto. Ao doutorando Lucas Costa pela constante ajuda. À PAPq pelo financiamento a pesquisa, à UEMG e à FaEnge.

\section{REFERÊNCIAS}

1 Szekely J, llegbusi OJ. The physical and mathematical modeling of tundish operations. New York: Editora Springer-Verlag; 1988.

2 Neves L. Modelamento matemático do escoamento multifásico no desgaseificador RH e no distribuidor de lingotamento contínuo [dissertação de doutorado]. Belo Horizonte: Pós-Graduação em Engenharias Metalúrgica e de Minas, UFMG; 2012.

3 Singh S, Koria SC. Tundish steel melt dynamics with and without flow modifiers through physical modeling. Ironmaking and Steelmaking. 1996;23(3):225-263.

4 Paladino EE. Estudo do escoamento multifásico em medidores de pressão do tipo pressão diferencial [tese de doutorado]. Florianópolis: Universidade Federal de Santa Catarina; 2005.

5 Ressel F. Introduction to Multiphase Flow Modelinf. Workshop \#1, \#2, \#3 e \#4, ESSS; 2008.

6 Barbosa FA. Modelamento matemático e físico do escoamento do aço líquido em diferentes projetos de distribuidor do lingotamento contínuo da Usiminas [dissertação de mestrado]. Belo Horizonte: Curso de Pós-Graduação em Engenharias Metalúrgica e de Minas, UFMG; 2002.

7 Sahai Y, Emi T. Melt Flow Characterization in continuous casting tundishes, ISIJ International. 1996;36(6):667-672.

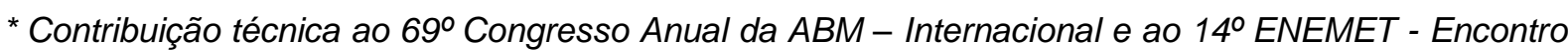
Nacional de Estudantes de Engenharia Metalúrgica, de Materiais e de Minas, 21 a 25 de julho de 2014, São Paulo, SP, Brasil.
} 